\title{
Population Psychology
}

National Cancer Institute

\section{Source}

National Cancer Institute. Population Psychology. NCI Thesaurus. Code C18950.

The branch of psychology that studies individual behavior as it relates to population processes. 